\title{
REAL OPTION AND VERTICAL MIXED-USE DEVELOPMENT
}

\author{
Jiawei ZHONG (1) ${ }^{1,}$, Eddie C. M. HUI (1) ${ }^{2}$ \\ ${ }^{1}$ School of Geography and Planning, Department of Urban and Regional Planning, \\ Sun Yat-Sen University, Guangzhou, China \\ ${ }^{2}$ Department of Building and Real Estate, The Hong Kong Polytechnic University, \\ Hung Hom, Kowloon, Hong Kong SAR
}

Received 07 August 2020; accepted 30 March 2021

\begin{abstract}
Vertical mixed-use development is a favourite choice in urban development in high-density Asian cities to increase the land use efficiency. The flexibility of construction timing and the restrictions by lease contracts in vertical mixeduse projects are usually different from horizontal ones and single-use properties. To improve the valuation for vertical mixed-use projects, this study re-examines the real option pricing model. Simultaneous development for different uses and a finite maximum waiting period are the major characteristics of these projects. An approach is introduced to determine whether to develop a mixed-use project vertically or horizontally on the basis of a statistics called the critical height premium. The vertical mixed-use project pricing model can be further verified by containing a height premium if market price information is derived from non-vertical mixed-use properties. This study suggests a more comprehensive real option approach to quantify the advantages and disadvantages of operating vertical mixed-use developments.
\end{abstract}

Keywords: vertical, mixed-use development, real option, height premium.

\section{Introduction}

Mixed-use development is an efficient option to achieve sustainable development in metropolitan areas, where the high population density requires great efficiency in urban land use (Walker, 1997). A successful mixed-use development is believed to enhance mixed property values, reduce the investment risk by diversification, improve energy efficiency, alleviate traffic congestion, increase residents and tenants' satisfaction, integrate public uses and increase the municipal revenues (Rabianski et al., 2009; Rowley, 1996; Planning Department, 2002; Walker, 1997). As a feasible solution to achieve sustainable development, it is also adopted as a pattern of redevelopment in the old town district.

The term "mixed-use development" usually refers to the horizontal dimension or mixed-use form-based zoning. The planning department incorporates different kinds of land use within the same administrative district. On the one hand, the commercial zone and the residential zone are planned in the same district. Thus, some residents can shorten their travel time to work. A comprehensive district with both retail properties and residential properties can increase the accessibility and then the attractiveness of both types of properties. On the other hand, some zones are assigned as flexible land use. In these zones, the developer can predetermine the actual proportions of different types of land use on the basis of the market environment. For example, the comprehensive development area and commercial/residential zone in Hong Kong, the white site and the business park-white site in Singapore have been representatives of flexible land use zoning since 1995. Mixed-use development is majorly applied in urban renewal programmes or high-density cities in Europe. In the U.S., this concept is combined with new types of urbanisation, such as smart growth and neotraditional neighbourhoods (Rabianski et al., 2009). Battery Park City in New York and Yebisu Garden Place in Tokyo are two representatives of horizontal mixed-use development (Cybriwsky, 1999). Commercial, recreational, retail and residential properties are included in these comprehensive development zones.

In several Asian cities, population pressure encourages the appearance of large-scale mixed-use developments (Lau et al., 2003), including plenty of vertical mixed-use buildings. For example, Hong Kong and Singapore, two Asian metropolitan areas, have planned and built highrise mixed-use properties for more than 30 years (Zhang, 2000). The integrated "rail-property" development model

*Corresponding author. E-mail: zhongjw29@mail.sysu.edu.cn 
in Hong Kong has successfully obtained the objective to finance the subway construction and operation cost. Over 10 multiple intensive land use (MILU) developments were constructed along the mass transit railway (MTR) upon the MTR stations. For retail and residential mixed properties, Mei Foo Sun Chuen, Metro City and Whampoa Garden are famous large-scale vertical mixed-use estates. As one of the vertical mixed-use designs, the podium style is accepted to combine a multi-level shopping mall with separate residential buildings and a green public space at the top of the shopping mall, which is called the "podium". Additionally, the heights of the podiums in nearby buildings are usually the same. Then, the passenger can cross the road though the bridge between two buildings. This structure can also be found in Shanghai, Singapore and Tokyo (Zhu \& Chiu, 2011). In Singapore, the Guoco Tower and South Beach are two new complex properties, comprising offices, hotels, retail spaces and luxury residential units. They contribute to the efficient use of common resources and are becoming new landmarks in the central business district (Jones Lang LaSalle, 2017). These vertical mixed-use properties can also attract more renters, residents and customers and increase public space. Hence, they play an important role in urban revitalisation.

To achieve the synthesised goals in the mixed-use development, comprehensive analyses should be conducted in advance. The demand of potential customers, the satisfaction of local residents and tenants, the support of public transportation facilities to manage high passenger flow, the sense of community, the financial profitability and the environmentally friendly issues are included in these analyses (Rabianski et al., 2009). Although the successful performances of mixed-use development have been supported in empirical studies (Bookout, 1992; Levine \& Frank, 2007; Frank \& Pivo, 1994; Kockelman, 1997; Nasar \& Julian, 1995; Geoghegan et al., 1997), mixed-use developments, especially vertical cases, require higher construction cost than single-use ones (Koch, 2004; Kettler, 2005).

This study contributes to the pricing for vertical mixed-use developments. They have two characteristics that are different from horizontal developments in the past research about real options. Firstly, properties in different uses have to be constructed at the same time. The developer would not rent out the retail units in the podium structure when the above residential buildings are still in construction. Secondly, the project is bounded by a land lease, with pre-determined building covenants and a finite period to complete the construction. Hence, a finite American basket option model written on two assets should be adopted.

This study will conduct a comprehensive literature review about the mixed-use development pricing approaches, especially the real option method in Section 1. Section 2 will present the main pricing model adopted by the authors to measure the values of vertical and horizontal types when the total building area is fixed. Besides a discussion about the influential factors on option values and expected exercise timing in Section 3, this section will also focus on the height premium in vertical mixed-use projects and provide an economic criteria to determine whether to develop horizontally or vertically. A summarisation of the major findings will be generalised in the last section.

\section{Literature review}

The price effects on nearby properties from mixed-use developments have been discussed in several studies. Positive premiums of single-family homes are found in Kentland where a residential and retail mixed-use community has been developed (Tu \& Eppli, 1999). The existence of similar premiums is also proven in Tucson (Van Cao \& Cory, 1982) and Portland, Oregon (Song \& Knaap, 2004). Office tenants also accept higher rents for locating into mixeduse developments because of a diversity of commercial activities (Vreeker et al., 2004; Liusman et al., 2017). However, Crafts (1998) did not find significant effects from a neighbouring shopping centre in New Hampshire. Some studies have even captured the negative residential price effect from a close commercial region (Mahan et al., 2000; Matthews \& Turnbull, 2007). Although the impacts on prices are conflicting in different studies, the popularity of mixed-use developments in recent decades is still verified (Rabianski et al., 2009). The developer continues to improve the accuracy in project pricing models.

At present, major approaches to value mixed-use projects are similar to single-use projects. Rabianski et al. (2009) summarised the value considerations in mixeduse developments in the traditional methods, including the sales comparison approach, the cost approach and the income approach (Ventolo \& Williams, 2005; Fisher \& Martin, 2007). These traditional approaches assume that the construction process starts immediately and that the income/sales revenue is generated when the construction is finished. The potential profit when delaying the construction is usually ignored.

The difficulty to operate empirical studies on mixeduse development value is attributed to the ambiguity of the data, e.g. the heterogeneity of different projects, ambiguous classification for multi-phase projects and ambiguous classification for some vertical mixed-use buildings where only the ground floor is for retail use (DeLisle \& Grissom, 2013).

Capozza and Li (1994) discussed the one-time land conversion option from one use to another. They showed how the land rents for both uses influence the conversion time and development density. Then, Geltner et al. (1996) applied the real option approach to investigate the optimal decision in a mixed-use development. This development contained two alternative land uses. The land value was generated as a function of two underlying assets, with the optimal decision to build a property in only one selected use. The land use choice was found to delay the 
development compared with single-use land. If two alternative land uses had the same value, the optimal decision prevents the land from being developed.

Childs et al. (1996) extended the conclusions from these two studies (Capozza \& Li, 1994; Geltner et al., 1996) to multi-conversion redevelopment cases. In the research, properties for two uses had already existed on the land. The redevelopment aimed to switch the proportion of land from use 1 to use 2 (or from use 2 to use 1 ) to optimise the land revenue on the basis of two market prices. The authors proved that the "all or nothing" strategy in previous studies was only applicable under the constant marginal revenues to scale assumptions. If the marginal revenues to scale were declining, equal values for two alternative uses might not delay the development.

Hughen and Read (2017) summarised the option pricing process in the form-based zoning structure, which is a mixed-use development including residential and commercial areas. At the beginning of development, the developer solves the optimisation problem to determine the optimal proportion for each use. Linear programming approach is suggested in this step (Addae-Dapaah, 2005). After the construction, the developer has a conversion chance to change a proportion of properties from use 1 into use 2 (or change a proportion of properties from use 2 into use 1) on the basis of the new market information. This option is additional and can be priced from the model suggested by Childs et al. (1996). Although form-based zoning encourages mixed-use development, the developer would only determine to build mixed-use properties for three reasons: the conversion option is permitted, construction costs are low enough, and revenues are significantly sensitive to residential or commercial supply. The importance of conversion option is emphasised in Hughen and Read's study.

Previous research has focused on the proportion changes between different uses in a mixed-use project. However, these discussions may not be applicable to all kinds of mixed-use developments. Hoppenbrouwer and Louw (2005) pointed out that in a spatial aspect, mixeduse projects should be divided into horizontal and vertical development. The major difference between horizontal and vertical is whether the multiple uses are located in the same building or just separated on the ground.

Numerous mixed-use projects in Europe and the U.S. are planned horizontally to ensure the flexibility of the construction process. The conversion opportunity in the mixed-use project usually exists in this horizontal type and allows the developer to alter the use in some completed buildings. However, in Asian cities, such as Hong Kong, Tokyo, Singapore and Shanghai, the high population pressure urges the government to support MILU developments (Zhu \& Chiu, 2011). Different uses, e.g. residential units, retail units, public transportation facilities and carparks, are usually vertically distributed within these MILU developments.
Traditional pricing methods, such as the sales comparison approach, the cost approach and the income approach, are still widely accepted in the empirical valuations of vertical developments (Rabianski et al., 2009). In these methods, the project values of horizontal developments should have small differences from those of vertical developments. The cost of vertical developments should be larger for some special designs to satisfy the needs and safety conditions of different uses in the building structure. The higher income of vertical developments should be based on the higher value of the residential/office use units on higher floors, as the maximum plot ratio of each use is bounded.

Existing option pricing models are more suitable for horizontal mixed-use projects (Capozza \& Li, 1994; Geltner et al., 1996; Childs et al., 1996; Addae-Dapaah, 2005; Hughen \& Read, 2017). However, the conversion of uses in the vertical type is usually difficult. This challenge comes from the simultaneous construction of the vertical mixed-use building. Different parts of this building have to follow the construction codes for specific uses. In other words, when the construction process starts, the proportion for each use should be determined and approved by the government. However, buildings in horizontal mixeduse programmes can be built separately. This ability to construct separately indicates that the developer still has a chance to reconsider the use for the latter one to be built even if the former structure is completed.

Besides the option pricing model for vertical mixeduse developments, this study will also compare the option value between vertical and horizontal mixed-use developments. In large cities, most mixed-use development programmes are restricted by the land lease, and some programmes are required to be developed vertically only. However, the comparison between two types of developments still makes sense. Firstly, before the acquisition of land, the developer can compare the real option value when the programme can be developed vertically or horizontally, and the option value when this programme can only be developed vertically. If the difference between two values is large enough, the developer can consider paying for an additional cost to change the land lease if possible. Second, if a project is not profitable enough when it is vertically developed, no developer will accept the project, and the restriction in the land lease may be loosened after a long period. Hence, the comparison between option values in the two types can increase the developer's choices before the acceptance of the development programme. Additionally, this comparison can emphasise the differences in the valuation process for the two types.

This study will examine how potential factors influence the option value and the expected starting time. Then, a comparison between vertical type and horizontal type will be conducted in the valuation aspect to determine the critical value to adopt vertical type or horizontal type in the planning stage. 


\section{Real option model for vertical mixed-use development}

\subsection{Basic model}

A vertical mixed-use development project consists of different types of land use within one building. This type of development usually follows a predetermined lease contract. In other words, the maximum development period is constrained by the lease contract. The real option for this project is demonstrated as a finite-time American call option.

For instance, in a simple case, only two types of land use exist in a vertical mixed-use development project. They are denoted as Type 1 and Type 2. The respective unit market prices are $S_{1}(t)$ and $S_{2}(t)$. In addition, the respective unit construction costs are $K_{1}(t)$ and $K_{2}(t)$. For the unit market prices, they are assumed to follow the geometric Brownian motions:

$$
\begin{aligned}
& d S_{1}(t)=v_{S 1} S_{1} d t+\sigma_{S 1} S_{1} d Z_{S 1} ; \\
& d S_{2}(t)=v_{S 2} S_{2} d t+\sigma_{S 2} S_{2} d Z_{S 2} ; \\
& \operatorname{Cov}\left(Z_{S 1}, Z_{S 2}\right)=\rho \sigma_{S 1} \sigma_{S 2} .
\end{aligned}
$$

The covariance assumption is a common mathematical assumption to enlarge the application range of the real option. In real estate development, a nearby retail property can usually promote the market price of residential properties (Shen et al., 2020; Wilhelmsson \& Long, 2020; Zhang et al., 2019). High-rise residential buildings can also provide sufficient customers for retail properties. Hence, the market prices between properties in different uses should not be independent from each other. Compared with the market price, the fluctuation of construction cost is much smaller. Supposing that the construction costs increase at a constant annual rate:

$$
\begin{aligned}
& d K_{1}(t)=\mu_{1} K_{1} d t, \\
& d K_{2}(t)=\mu_{2} K_{2} d t .
\end{aligned}
$$

The appreciation rates of these two construction costs should not be equal to zero at the same time. If $\mu_{1}=\mu_{2}=0$, the construction costs are maintained at a constant level. Then, the optimal strategy is to start the construction until the end of the maximum exercise period. The finite-time American call option has the same value and the same strategy as a European call option with identical parameters. Similarly, $\mu_{1}<0$ or $\mu_{2}<0$ indicates the delay of development. Here, both $\mu_{1}$ and $\mu_{2}$ are assumed as positive.

This study focuses on the development programme without the vertical expansion option. In other words, the different kinds of properties within the project are designed and completed in a single construction process. Although the vertical expansion option is more profitable for commercial mixed-use development in some actual scenarios (Guma et al., 2009; Pearson \& Wittels, 2008), these scenarios usually do not contain the residential units for sale in the project. When residential units are sold to purchasers, they can live in these units for decades. The developer cannot ask the residents to move out for verti- cal expansion. Hence, the existing project is difficult to be expanded when residential units are included in the initial design. The expansion of vertical mixed-use development can be embedded into the model in future studies.

Notably, when the lease contract comes into effect, the developer will be delivered the vacant land instead of an old property to be demolished. Hence, it is a one-phase redevelopment project. To maximise the profit, the developer tends to maximise the difference between property market prices and construction cost during the required construction period, i.e.:

$$
\begin{aligned}
& V\left(S_{1}(t), S_{2}(t), K_{1}(t), K_{2}(t)\right)= \\
& \operatorname{Max}\left\{\begin{array}{l}
K_{1}(t) \cdot A_{1}-K_{2}(t) \cdot A_{2}- \\
K_{1}(t) \cdot A_{1}+S_{2}(t) \cdot A_{2}- \\
\left.C, e^{-r \Delta t} E\left[\begin{array}{l}
S_{1}(t+\Delta t), S_{2}(t+\Delta t), \\
K_{1}(t+\Delta t), K_{2}(t+\Delta t)
\end{array}\right)\right]
\end{array}\right\} ; \\
& (0 \leq t \leq T),
\end{aligned}
$$

where: $C$ represents the other fixed costs during the construction process that are independent of the construction floor area (CFA). $A_{1}$ and $A_{2}$ are the CFA of Type 1 and Type 2. The term $e^{-r \Delta t} E\left[V\left(S_{1}(t+\Delta t), S_{2}(t+\Delta t), K_{1}(t+\Delta t), K_{2}(t+\Delta t)\right)\right]$ stands for the present value of this option if it is not exercised at time t. $r$ is the risk-free interest rate.

As a boundary condition, the option value at the end of the maximum construction period is

$$
\begin{aligned}
& V\left(S_{1}(t), S_{2}(t), K_{1}(t), K_{2}(t)\right)= \\
& \operatorname{Max}\left\{\begin{array}{l}
0, S_{1}(T) \cdot A_{1}+S_{2}(T) \cdot A_{2}- \\
K_{1}(T) \cdot A_{1}-K_{2}(T) \cdot A_{2}-C
\end{array}\right\},
\end{aligned}
$$

where: $T$ is the maximum exercise period. This real option is an American finite-time call option written on multiple assets. The analytical solution does not exist. Instead, numerical simulation results can be generated from the Monte Carlo approach. In this study, the least square Monte Carlo (LSMC) method suggested by Longstaff and Schwartz (2001) is adopted, with an extension of multiasset scenarios.

\subsection{Least square Monte Carlo method}

Longstaff and Schwartz (2001) derived an approach to find the value of an American finite-time option based on the optimal exercise strategy. The LSMC approach is available on American put options or American call options with dividends. If we select the cost of carrying the underlying real asset as the asset drift rate, the yield rate of developed properties is equivalent to the dividend in a financial American option (Merton, 1973; Yao \& Pretorius, 2014). Hence, the LSMC approach is applicable to this real option based on a revision of Hoyle's algorithm (2016). 
A necessary adjustment to the traditional LSMC approach is the multi-asset background in a vertical mixeduse development. Longstaff and Schwartz (2001) suggested the Laguerre polynomials as basis functions in the least squares regression in the single-asset case. However, the cross items between different assets should be included as basis functions in the multi-asset case. As Glasserman and $\mathrm{Yu}$ (2004) discussed for the required number of paths and the number of basis functions in LSMC estimation, the degrees of monomials for each asset is constrained as no more than two (Abbas-Turki \& Lapeyre, 2009). To minimise the underestimation amount of the LSMC approach, we adopt the set of basis functions suggested by Coskan (2008), e.g.

$$
1, S_{1}, S_{2}, S_{1}^{2}, S_{2}^{2}, S_{1} S_{2}, S_{1}^{2} S_{2}, S_{1} S_{2}^{2}, S_{1}^{2} S_{2}^{2} \text {. }
$$

In each monomial, the degrees of $S_{1}$ and $S_{2}$ can be 0,1 or 2. The number of basis functions is $3^{2}$ in the two-asset case and $3^{3}$ in the three-asset case. This approach is available to the cases when the uses in a single building are no more than three different types. In some special projects when the uses are more than three, other advanced basis functions should be adopted, such as Laguerre, Hermite, Hyperbolic and Chebyshev polynomials.

\subsection{Market information}

To identify different types of properties in the mixeduse development, a preliminary study was conducted on residential and retail property markets in Hong Kong. This study finds some characteristics of these two markets, such as current prices, price volatilities, rental yields, construction costs and market correlation. The data come from the Rating and Valuation Department, the Buildings Department, the Census and Statistics Department and the Government Bond Programme in Hong Kong. Some commercial information also refers to the Arcadis Construction Cost Handbook in 2018 (Arcadis, 2018). These market characteristics are summarised in Table 1.

Table 1 . The characteristics of Hong Kong property markets

\begin{tabular}{|l|c|}
\hline \multicolumn{1}{|c|}{ Parameters } & Values \\
\hline Risk-free interest rate & $1.75 \%$ p.a. \\
\hline Rental yield for residential properties & $3.73 \%$ p.a. \\
\hline Rental yield for retail properties & $4.73 \%$ p.a. \\
\hline HKD prime rate & $5.00 \%$ p.a. \\
\hline Volatility of residential properties $\left(v_{1}\right)$ & $13.16 \%$ p.a. \\
\hline Volatility of retail properties $\left(v_{2}\right)$ & $41.91 \%$ p.a. \\
\hline Residential unit price (per sq.m.) & 126679 HKD \\
\hline $\begin{array}{l}\text { Retail unit price (per sq.m.) (based on } \\
\text { transaction data) }\end{array}$ & 363328 HKD \\
\hline Residential unit cost (per sq.m.) & 26650 HKD \\
\hline Retail unit cost (per sq.m.) & 35650 HKD \\
\hline Increase rate of construction cost & $4.35 \%$ p.a. \\
\hline
\end{tabular}

Note: The retail unit price is estimated based on the monthly retail rent.
To investigate the option model in more common scenarios worldwide, the risk-free interest rate and the construction cost are set higher in the simulations to avoid the immediate exercise of the redevelopment option. The irregular high volatility of the retail market is reduced. The total gross floor area (GFA) of this development is assumed as the same as that of the Kung Tong Town Centre Project (https://www.ura.org.hk/en/project/ redevelopment/kwun-tong-town-centre-project). Only the residential use and the commercial/retail of the project are included in this simulation.

\section{Vertical development and horizontal development}

\subsection{Basic assumptions}

As mentioned in the literature review, the horizontal type of mixed-use projects is more common in urban planning. In the planning stage, the developer may face a problem in selecting between these two types. This dilemma can be investigated in the aspects of social need, building design and environment. In this study, we will only apply the real option approach to find the more profitable type in the economic aspect.

To transfer real projects into real option scenarios, several assumptions need to be made to compare the project costs and revenues.

Assumption 1. The GFA and the CFA for both uses in the vertical type are equal to those in the horizontal type. The construction cost per square metre of the CFA (and then the GFA) for the lower structure in the vertical type is also equal to that in the same use in the horizontal type. For the upper structure in the vertical type, the construction cost is separated into two parts. One is equal to the construction cost in the same use in the horizontal type. The other one is the additional cost for a high-rise vertical structure, which is a function of the construction cost in the same use in the horizontal type.

This assumption firstly excludes the difference in the GFA and the CFA before the comparison. The construction cost per square metre of the CFA is transferred into the cost per square metre of the GFA before the application of real option models. In the actual valuation, an additional cost is included in the vertical project valuation, as the building design of the vertical one is usually more complicated than that of the horizontal one. This additional cost is further discussed in Section 3.3.

Assumption 2. The advantage of the horizontal type comes from the higher flexibility in the construction timing for separate buildings in different uses.

This feature is the major difference between the real option approach and other valuation methods (e.g. the sales comparison approach, the cost approach and the income approach). The value of the optimal construction timing is emphasised in the real option approach.

In the horizontal development, the two different uses are separated in two buildings, and their construction 
timings can be different. Although the construction process of the latter building may have negative externality on the former completed one, this externality is only temporary and can even be excluded when the construction period is assumed to be very short. In the vertical development, however, these two uses have to be built and sold jointly. In other words, the developer can construct the two buildings with different uses at their separate optimal timings in the horizontal development. Meanwhile, the vertical mixed-use building only has a single optimal chance for construction.

The presales process can change the precondition that the retail units and residential units should be sold after the completion of the whole mixed-use development programme. In detail, the retail units will not be presold. The residential units can be presold when the building progress of the whole project has achieved several required conditions, such as the percentage of completion and the maximum term of delivery. These requirements are adopted to protect potential residents. However, the residential units in the horizontal mixed-use development can also be presold when the building progress of residential buildings has achieved the requirements. Whether the retail units are completed does not influence the presales of the residential units in horizontal mixed-use development. Hence, the presales timing of residential units in the horizontal type is still more flexible than that in the vertical type.

In each decision period, the option value of the whole horizontal mixed-use project is:

$$
\begin{aligned}
& V\left(S_{1}(t), K_{1}(t)\right)+V\left(S_{2}(t), K_{2}(t)\right)= \\
& \operatorname{Max}\left\{\begin{array}{l}
0, S_{1}(t) \cdot A_{1}-K_{1}(t) \cdot A_{1}, \\
e^{-r \Delta t} E\left[V\left(S_{1}(t+\Delta t), K_{1}(t+\Delta t)\right)\right]
\end{array}\right\}+ \\
& \operatorname{Max}\left\{\begin{array}{l}
0, S_{2}(t) \cdot A_{2}-K_{2}(t) \cdot A_{2}, \\
e^{-r \Delta t} E\left[V\left(S_{2}(t+\Delta t), K_{2}(t+\Delta t)\right)\right]
\end{array}\right\} .
\end{aligned}
$$

At the same period, the option value of the whole vertical mixed-use project is:

$$
\begin{aligned}
& V\left(S_{1}(t), S_{2}(t), K_{1}(t), K_{2}(t)\right)= \\
& \operatorname{Max}\left\{\begin{array}{l}
0, S_{1}(t) \cdot A_{1}+S_{2}(t) \cdot A_{2}- \\
K_{1}(t) \cdot A_{1}-K_{2}(t) \cdot A_{2}- \\
\left.C, e^{-r \Delta t} E\left[\begin{array}{l}
S_{1}(t+\Delta t), S_{2}(t+\Delta t), \\
K_{1}(t+\Delta t), K_{2}(t+\Delta t)
\end{array}\right)\right]
\end{array}\right\} \\
& (0 \leq t \leq T) .
\end{aligned}
$$

As the inequality of maximum is always held:

$$
\operatorname{Max}(A+B) \leq \operatorname{Max}(A)+\operatorname{Max}(B) \text {. }
$$

We have

$$
\begin{aligned}
& \operatorname{Max}\left[0, S_{1}(t) \cdot A_{1}+S_{2}(t) \cdot A_{2}-K_{1}(t) \cdot A_{1}-K_{2}(t) \cdot A_{2}-C\right] \leq \\
& \operatorname{Max}\left[0, S_{1}(t) \cdot A_{1}+S_{2}(t) \cdot A_{2}-K_{1}(t) \cdot A_{1}-K_{2}(t) \cdot A_{2}\right] \leq \\
& \operatorname{Max}\left[0, S_{1}(t) \cdot A_{1}-K_{1}(t) \cdot A_{1}\right]+\operatorname{Max}\left[0, S_{2}(t) \cdot A_{2}-K_{2}(t) \cdot A_{2}\right] \\
& (0 \leq t \leq T)
\end{aligned}
$$

and then

$$
\begin{aligned}
& \operatorname{Max}\left\{e^{-r \Delta t} E\left[V\left(S_{1}(t+\Delta t), S_{2}(t+\Delta t), K_{1}(t+\Delta t), K_{2}(t+\Delta t)\right)\right]\right\} \leq \\
& \operatorname{Max}\left\{e^{-r \Delta t} E\left[V\left(S_{1}(t+\Delta t), K_{1}(t+\Delta t)\right)\right]\right\}+ \\
& \operatorname{Max}\left\{e^{-r \Delta t} E\left[V\left(S_{2}(t+\Delta t), K_{2}(t+\Delta t)\right)\right]\right\} .
\end{aligned}
$$

Hence,

$V\left(S_{1}(t), S_{2}(t), K_{1}(t), K_{2}(t)\right) \leq V\left(S_{1}(t), K_{1}(t)\right)+$ $V\left(S_{2}(t), K_{2}(t)\right)$.

The above proof explains the advantage of horizontal projects when the developer can select the optimal timing to start the construction.

Assumption 3. The advantage of the vertical type comes from the higher market value of the upper structure for a different use than the value of the separated building for the same use in the horizontal type.

This assumption excludes the case in which the horizontal mixed-use development is unavailable. That is, the land size is too small to build two separate buildings under the building regulations. Moreover, the vertical development can increase the height of the upper structure whose use is different from the lower structure. This feature can significantly increase the value of the upper structure especially when it is for residential use.

Several empirical studies and interviews have proven that the residents' preference of higher floors exists in the apartment type of residential housing (Mok et al., 1995; Bao \& Wan, 2004; Lai et al., 2007; Choy et al., 2007; Hui et al., 2007, 2012; Jim \& Chen, 2009, 2010; Xiao et al., 2019). Among these reasons are better scenic views, less disturbance from the street and less influence from air and noise pollution in the higher floor units.

To reduce the value loss in the lower residential units, the podium model has been promoted since the 1980s. The lower structure, i.e. the podium, is for retail use. Being located in the lower floors is usually not viewed as a disadvantage for the shops. The upper structure is usually a residential building on the podium. This arrangement increases the height of the residential building, especially for the lower floor units. The podium works as an artificial ground floor for the residential buildings over the commercial part. As a result, the market value of the residential building is expected to be higher in the vertical development than in the horizontal one. Even the units on the second floor of these buildings are significantly away from the real streets (Lau \& Zhang, 2015).

Assumption 4. The height premium of the upper structure in the vertical development is based on the hedonic 
pricing model, which is compared with the separate building for the same use in the horizontal development.

To make the two types of developments more comparable, the upper structure in the vertical project is assumed to have the same design as a separate building for the same use in the horizontal project. This case can be extended to multiple residential buildings located around the top of the podium when the horizontal development also contains multiple residential buildings. Notably, not all the space on the top of the podium is used for the upper structure.

\subsection{Model descriptions}

We suppose that the height of the podium is equivalent to the height of $X$ floors in the residential building. For example, the height of the podium in Hong Kong is usually 15 metres. According to the Building (Planning) Regulations (Cap. 123, section 38), the minimum height in each storey should be $2.5 \mathrm{~m}$. Then, $X=6$ in this case. Hence, the value of a residential unit on the $N$ floor in the vertical development is equal to the value of a residential unit on the $N+X$ floor in the horizontal one when other structural attributes are kept consistent. According to the hedonic pricing model (Rosen, 1974), the relationship among the property value $(P)$, the floor number $(N)$ and the other potential attributes $(A)$ is:

$$
\operatorname{Ln} P=\alpha \times N+\beta \times A,
$$

or

$$
P=e^{\alpha \cdot N} \cdot e^{\beta \cdot A},
$$

where: $\alpha$ is the coefficient of the floor on property value, and $\beta$ is the coefficient vector which measures the effects of other attributes $A$ on the property value.

We denote the value of a residential unit on the $N$ floor in the vertical development as $P_{1}$ and the value of another unit on the $\mathrm{N}$ floor in the horizontal development as $P_{2}$. Then,

$$
P_{1}=e^{\alpha \cdot X} \cdot P_{2}
$$

when the other attributes are equal.

We denote the unit market price of the residential part in the vertical project as $S_{1}(t)$ and the unit price of the retail/commercial part as $S_{2}(t)$. Then, based on Assumptions 1 and 4 , the unit price of a residential building in the horizontal project is $S_{1}(t) \times e^{-\alpha \times X}$. The unit price of commercial building is still $S_{2}(t)$, as the commercial building value is not sensitive to the building height.

Then, the total value of the vertical development should be

$$
\begin{aligned}
& V\left(S_{1}(t), S_{2}(t), K_{1}(t), K_{2}(t)\right)= \\
& \operatorname{Max}\left\{\begin{array}{l}
0, S_{1}(t) \cdot A_{1}+S_{2}(t) \cdot A_{2}- \\
K_{1}(t) \cdot A_{1}-K_{2}(t) \cdot A_{2}, \\
e^{-r \Delta t} E\left[V\left(\begin{array}{l}
S_{1}(t+\Delta t), S_{2}(t+\Delta t), \\
K_{1}(t+\Delta t), K_{2}(t+\Delta t)
\end{array}\right)\right]
\end{array}\right\}
\end{aligned}
$$$$
(0 \leq t \leq T) \text {, }
$$

where: $K_{1}(t)$ and $K_{2}(t)$ are the average construction cost in the residential and retail parts of this mixed-use development, respectively.

The total value of the horizontal development becomes

$$
\begin{aligned}
& V\left(S_{1}(t), K_{1}(t)\right)+V\left(S_{2}(t), K_{2}(t)\right)= \\
& \operatorname{Max}\left\{\begin{array}{l}
0, S_{1}(t) \cdot e^{-\alpha \times X} \cdot A_{1}- \\
K_{1}(t) \cdot A_{1}+C, \\
e^{-r \Delta t} E\left[V\left(S_{1}(t+\Delta t), K_{1}(t+\Delta t)\right)\right]
\end{array}\right\}+ \\
& \operatorname{Max}\left\{\begin{array}{l}
0, S_{2}(t) \cdot A_{2}-K_{2}(t) \cdot A_{2}, \\
e^{-r \Delta t} E\left[V\left(S_{2}(t+\Delta t), K_{2}(t+\Delta t)\right)\right]
\end{array}\right\},
\end{aligned}
$$

where: $C$ stands for the additional construction cost in the vertical development compared with the horizontal one. The other symbols are the same as those in previous discussions. $e^{-\alpha \times X}$ is the height premium term. If $S_{1}(t)$, $K_{1}(t)$ are based on the market price of the horizontal development, the option value of the vertical types should be written as:

$$
\begin{aligned}
& V\left(S_{1}(t), S_{2}(t), K_{1}(t), K_{2}(t)\right)= \\
& \operatorname{Max}\left\{\begin{array}{l}
0, S_{1}(t) \cdot e^{\alpha \times X} \cdot A_{1}+S_{2}(t) \cdot A_{2}- \\
K_{1}(t) \cdot A_{1}-K_{2}(t) \cdot A_{2}- \\
\left.C, e^{-r \Delta t} E\left[\begin{array}{l}
S_{1}(t+\Delta t), S_{2}(t+\Delta t), \\
K_{1}(t+\Delta t), K_{2}(t+\Delta t)
\end{array}\right)\right]
\end{array}\right\} \\
& (0 \leq t \leq T) .
\end{aligned}
$$

In the following discussion, Formulas (3) and (4) are applied.

The hurdle value of $e^{-\alpha \times X}$ does not have an analytical solution. However, we can estimate it from the Monte Carlo simulations in the following procedures:

Step 1. Estimate the option values of $V\left(S_{1}(t), S_{2}(t)\right.$, $\left.K_{1}(t), K_{2}(t)\right), V\left(S_{1}(t), K_{1}(t)\right)$ and $V\left(S_{2}(t), K_{2}(t)\right)$.

Step 2. Calculate the hurdle value of $V\left(S_{1}(t), K_{1}(t)\right)$ if the equation $V\left(S_{1}(t), S_{2}(t), K_{1}(t), K_{2}(t)\right)=V\left(S_{1}(t)\right.$,

$\left.K_{1}(t)\right)+V\left(S_{2}(t), K_{2}(t)\right)$ is satisfied. Then, denote the value as $\hat{V}\left(S_{1}(t), K_{1}(t)\right)$.

Step 3. On the basis of the ratio $V\left(S_{1}(t), K_{1}(t)\right) /$ $\hat{V}\left(S_{1}(t), K_{1}(t)\right)$, substitute the value

$$
\left(\frac{V\left(S_{1}(t), K_{1}(t)\right)}{\hat{V}\left(S_{1}(t), K_{1}(t)\right)}-1\right) \times 0.5
$$

into $e^{\alpha \times X}$ and estimate the new option value of $V\left(S_{1}(t), K_{1}(t)\right)$. Denote this option value as $\tilde{V}\left(s_{1}(t), K_{1}(t)\right)$. 
Step 4. Compare $\tilde{V}\left(S_{1}(t), K_{1}(t)\right)$ and $V\left(S_{1}(t), K_{1}(t)\right)$. If $\tilde{V}\left(S_{1}(t), K_{1}(t)\right)>\hat{V}\left(S_{1}(t), K_{1}(t)\right)$, increase the value of $e^{\alpha \times X}$ and replace the value of $\tilde{V}\left(S_{1}(t), K_{1}(t)\right)$. If $\tilde{V}\left(S_{1}(t), K_{1}(t)\right)<\hat{V}\left(S_{1}(t), K_{1}(t)\right)$, decrease the value of $e^{\alpha \times X}$ and replace the value of $\tilde{V}\left(S_{1}(t), K_{1}(t)\right)$.

Step 5. Repeat Step 4 until the difference between $\tilde{V}\left(S_{1}(t), K_{1}(t)\right)$ and $\hat{V}\left(S_{1}(t), K_{1}(t)\right)$ is small enough.

In the actual comparison, the estimation of the option value by Monte Carlo simulations may have small variations when the sample paths change. The value of $e^{-\alpha \times X}$ cannot change continuously, either. In this study, we calculate two values on the basis of $\hat{V}\left(S_{1}(t), K_{1}(t)\right)$.

$$
\begin{aligned}
& \hat{V}_{1}\left(S_{1}(t), K_{1}(t)\right)=99.5 \% \times \hat{V}\left(S_{1}(t), K_{1}(t)\right), \\
& \hat{V}_{2}\left(S_{1}(t), K_{1}(t)\right)=100.5 \% \times \hat{V}\left(S_{1}(t), K_{1}(t)\right) .
\end{aligned}
$$

When estimating $\tilde{V}\left(S_{1}(t), K_{1}(t) \mid e^{\alpha \times X}\right)$, the value of $e^{\alpha \times X}$ changes at a minimum scale of $0.1 \%$. A maximum $\alpha_{1}$ exists, which satisfies

$$
\tilde{V}\left(S_{1}(t), K_{1}(t) \mid e^{\alpha_{1} \times X}\right)>\hat{V}_{2}\left(S_{1}(t), K_{1}(t)\right) .
$$

For any $\alpha$ smaller than $\alpha_{1}, \tilde{V}\left(S_{1}(t), K_{1}(t) \mid e^{\alpha \times X}\right)>$ $\hat{V}_{2}\left(S_{1}(t), K_{1}(t)\right)$. Then, the value of the horizontal project is larger than that of the vertical project:

$$
\begin{aligned}
& \tilde{V}\left(S_{1}(t), K_{1}(t) \mid e^{\alpha \times X}\right)+V\left(S_{2}(t), K_{2}(t)\right)> \\
& \hat{V}_{2}\left(S_{1}(t), K_{1}(t)\right)+V\left(S_{2}(t), K_{2}(t)\right)> \\
& V\left(S_{1}(t), S_{2}(t), K_{1}(t), K_{2}(t)\right) .
\end{aligned}
$$

This value indicates that when the height premium is smaller, the horizontal type is more economically profitable.

Similarly, a minimum $\alpha_{2}$, which satisfies

$$
\tilde{V}\left(S_{1}(t), K_{1}(t) \mid e^{\alpha_{2} \times X}\right)<\widehat{V}_{1}\left(S_{1}(t), K_{1}(t)\right),
$$

is another critical value.

For any $\alpha$ larger than $\alpha_{2}, \tilde{V}\left(S_{1}(t), K_{1}(t) \mid e^{\alpha \times X}\right)<$ $\hat{V}_{1}\left(S_{1}(t), K_{1}(t)\right)$. The value of the vertical project is larger.

$$
\begin{aligned}
& \tilde{V}\left(S_{1}(t), K_{1}(t) \mid e^{\alpha \times X}\right)+V\left(S_{2}(t), K_{2}(t)\right)< \\
& \hat{V}_{1}\left(S_{1}(t), K_{1}(t)\right)+V\left(S_{2}(t), K_{2}(t)\right)< \\
& V\left(S_{1}(t), S_{2}(t), K_{1}(t), K_{2}(t)\right) .
\end{aligned}
$$

A large height premium encourages the developer to select the vertical type.

\subsection{Further discussions about the additional construction cost $\mathrm{C}$}

In the main model, the difference in the construction cost between the vertical and horizontal types, $C$, is assumed to be a fixed cost. This cost is an estimated total based on the average construction cost in the previous projects. If the developer wants to estimate the construction cost more accurately, the construction cost can be a function of the floor number.
If the construction cost is a linear function of the floor number, then we suppose that the estimated coefficient of the linear term is $\gamma$. Assuming that the building area in each floor is the same, then the building area in each floor is $A_{1} / n$ for a building with $n$ floors. The average construction cost $K_{1}(\mathrm{t})$ is the construction cost in the middle floor. Then,

$$
C=\sum_{j=1}^{n} K_{1}(t) \cdot \gamma \cdot X \cdot \frac{A_{1}}{n}=K_{1}(t) \cdot \gamma \cdot X \cdot A_{1} .
$$

Notably, the sum of construction in floor $(n / 2-\mathrm{j})$ and floor $(n / 2+\mathrm{j})$ is only $2 K_{1}(t)$.

The case of the quadratic function is more complicated. For a high-rise building, $C>0$ is still satisfied. Moreover, $S_{1}(t)>K_{1}(t)$ is expected. $K_{1 s t}(t)$ denotes the average construction cost of the first floor. Then,

$$
C=K_{1 s t}(t) \cdot \gamma_{1} \cdot X \cdot A_{1}+K_{1 s t}(t) \cdot \gamma_{2} \cdot\left[(n+1) X+X^{2}\right] \cdot A_{1} \text {, }
$$

where: $\gamma_{1}$ and $\gamma_{2}$ are the coefficients of the linear term and the quadratic term based on the previous projects. $K_{1 s t}(t)$ can be derived from $K_{1}(t), \gamma_{1}, \gamma_{2}$ and $n$. Other parameters are known and fixed except $K_{1}(t)$.

$\gamma_{1}, \gamma_{2}, \gamma, n$ and $X$ are all known constants in a project. Then, $V\left(S_{1}(t), K_{1}(t)\right)$ is still a call option based on only $S_{1}(t)$ and $K_{1}(t)$, as $C$ can be written as a function of $K_{1}(t)$ only.

However, both the annual changes in construction cost and the range of construction cost in the same period are small. According to the Hong Kong Report of Quarterly Construction Cost Update in December 2020 by Rider Levett Bucknall (2020), the structure building cost of high-rise residential properties of ordinary quality is $14800-16100 \mathrm{HKD} / \mathrm{m}^{2}$, which is only a difference of 10\%. The Arcadis Construction Cost Handbook in 2020 also provides the total construction cost, which is the sum of structure building cost and service cost, of high-rise apartments of average standard as $23600-27300 \mathrm{HKD} / \mathrm{m}^{2}$. The structure building cost is $19700-21700 \mathrm{HKD} / \mathrm{m}^{2}$, which is also a difference of $10 \%$. Meanwhile, the average market price of a newly built residential property can vary from approximately $200000 \mathrm{HKD} / \mathrm{m}^{2}$ in Tseung Kwan O to approximately $300000 \mathrm{HKD} / \mathrm{m}^{2}$ in Tsim Sha Tsui. The difference is much larger in price than in cost, as the major difference comes from the difference in land values.

Additionally, estimating the coefficients of $\gamma, \gamma_{1}$ and $\gamma_{2}$ requires the construction cost information for a number of previous projects. The developer can easily achieve this information and make a more accurate cost analysis. However, as mentioned above, the estimation of the accurate building cost shows little influence on the option value pricing, as the market price usually has a much larger fluctuation than the construction cost. The accurate estimation of construction cost can be a further adjustment in the application of this option pricing model and will not change the major findings. 


\subsection{Simulation results and discussions}

To show the impact from the proportion and volatility of each use on the critical value, the initial market price and construction cost in the alternative horizontal project is assumed the same as those in the vertical project in Section 2. On the basis of the estimated option values of $V\left(S_{1}(t), K_{1}(t)\right)$ and $V\left(S_{2}(t), K_{2}(t)\right)$, we can achieve the hurdle option value $\hat{V}\left(S_{1}(t), K_{1}(t)\right)$, the hurdle ratio $\left(\frac{V\left(S_{1}(t), K_{1}(t)\right)}{\hat{V}\left(S_{1}(t), K_{1}(t)\right)}-1\right)$ and the pairs of critical height premium $\left[e^{\alpha_{1} \times X}-1, e^{\alpha_{2} \times X}-1\right]$ for each scenario. Here, the form of $\left[e^{\alpha_{1} \times X}-1, e^{\alpha_{2} \times X}-1\right]$ is used to show its trend compared with the trend of $\left(\frac{V\left(S_{1}(t), K_{1}(t)\right)}{\hat{V}\left(S_{1}(t), K_{1}(t)\right)}-1\right)$. On the basis of the estimated option values of individual buildings in the horizontal project, the trends of these three parameters can be observed from Table 2.

The critical height premium is the most important reference parameter to determine whether to select the vertical type or the horizontal type. If this premium increases, a higher height premium is required to comprise the time value loss when the buildings for the two uses have to be constructed at the same time. Then, the horizontal type is more likely to be accepted when this premium is difficult to achieve. The hurdle option value and the hurdle ratio do not directly influence the developer's decision. However, they can provide a better understanding of the trends of critical height premium when the volatilities vary.

If the lower boundary is zero, any positive height premium may discourage the developer to select the horizontal type.

The major findings include:

1. The trends of hurdle option values and the hurdle ratio $\left(\frac{V\left(S_{1}(t), K_{1}(t)\right)}{\hat{V}\left(S_{1}(t), K_{1}(t)\right)}-1\right)$ are opposite. The hurdle option value is positively related to the residential market volatility but negatively related to the retail market volatility. Both volatilities increase the total vertical project value and the proportion of the related building value in the horizontal project. The proportion of the residential building value and the total vertical project value are both positive factors of the hurdle option value.

However, when the hurdle option value is compared with the residential building value, the adverse trend becomes significant. In general, high residential market volatility reduces the hurdle ratio except when the retail market volatility is very low. This phenomenon can be explained by the comparison between Table 3 and Table 4 . The option values in the horizontal type and the vertical type are generated in these two tables, respectively. The total vertical project value rises more slowly than the residential/retail building value in the horizontal project as the residential/retail market volatility increases. The

Table 2. The hurdle option value, the hurdle ratio and the critical height premium in different scenarios

\begin{tabular}{|l|c|c|c|}
\hline \multicolumn{4}{|c|}{ Case 1 (original design): GFA1 = 151232 square meter, GFA2 = 209640 square meter } \\
\hline & $v_{1}=0.06$ & $v_{1}=0.13$ & $v_{1}=0.20$ \\
\hline$v_{2}=0.10$ & 7553.48 & 7592.25 & 7646.75 \\
& $0.12 \%$ & $0.58 \%$ & $4.05 \%$ \\
& {$[0,0.3 \%]$} & {$[0,0.1 \%]$} & {$[1.7 \%, 2.4 \%]$} \\
\hline$v_{2}=0.20$ & 6352.56 & 6804.43 & 7331.20 \\
& $19.05 \%$ & $12.23 \%$ & $8.53 \%$ \\
& {$[6.9 \%, 7.4 \%]$} & {$[5.0 \%, 5.5 \%]$} & {$[4.0 \%, 4.8 \%]$} \\
\hline$v_{2}=0.30$ & 5211.57 & 5449.11 & 6363.01 \\
& $45.11 \%$ & $40.14 \%$ & $25.04 \%$ \\
& {$[15.2 \%, 15.7 \%]$} & {$[15.6 \%, 16.2 \%]$} & {$[11.7 \%, 12.4 \%]$} \\
\hline
\end{tabular}

\begin{tabular}{|l|c|c|c|}
\hline \multicolumn{3}{|c|}{ Case 2: GFA1 288698 square meter $(80 \%$ GFA), GFA2 $=72174$ square meter $(20 \%$ GFA) } \\
\hline & $v_{1}=0.06$ & $v_{1}=0.13$ & $v_{1}=0.20$ \\
\hline$v_{2}=0.10$ & 14430.50 & 14493.78 & 14806.51 \\
& $0.04 \%$ & $0.58 \%$ & $2.58 \%$ \\
& {$[0,0.3 \%]$} & {$[0,0.4 \%]$} & {$[1.0 \%, 1.7 \%]$} \\
\hline$v_{2}=0.20$ & 13622.61 & 13979.51 & 14604.04 \\
& $5.97 \%$ & $4.28 \%$ & $4.00 \%$ \\
& {$[2.2 \%, 2.7 \%]$} & {$[1.4 \%, 2.1 \%]$} & {$[1.7 \%, 2.4 \%]$} \\
\hline$v_{2}=0.30$ & 12231.65 & 129.4180 & 14048.07 \\
& $18.03 \%$ & $12.64 \%$ & $8.12 \%$ \\
& {$[6.6 \%, 7.1 \%]$} & {$[5.1 \%, 5.8 \%]$} & {$[3.8 \%, 4.6 \%]$} \\
\hline
\end{tabular}

Note: $v_{1}$ is the volatility of the residential property market price, and $v_{2}$ is the volatility of the retail property market price. These scenarios are $50 \%$, $100 \%$, and $150 \%$ of the estimated $v_{1}$ and $v_{2}$ in Table 1 respectively. 
Table 3. The estimated option value for individual buildings in the horizontal development

\begin{tabular}{|l|c|c|c|}
\hline \multicolumn{3}{|c|}{ Case 1 (original design): GFA1 = 151232 square meter, GFA2 $=209640$ square meter } \\
\hline & $v_{1}=0.06$ & $v_{1}=0.13$ & $v_{1}=0.20$ \\
\hline$V\left(S_{1}(t), K_{1}(t)\right)$ & 7562.47 & 7636.39 & 7956.29 \\
\hline$V\left(S_{2}(t), K_{2}(t)\right)$ & $v_{2}=0.10$ & $v_{2}=0.20$ & $v_{2}=0.30$ \\
\hline
\end{tabular}

\begin{tabular}{|l|c|c|c|}
\hline \multicolumn{3}{|c|}{ Case 2: GFA1 $=288698$ square meter $(80 \%$ GFA), GFA2 $=72174$ square meter $(20 \%$ GFA) } \\
\hline & $v_{1}=0.06$ & $v_{1}=0.13$ & $v_{1}=0.20$ \\
\hline$V\left(S_{1}(t), K_{1}(t)\right)$ & 14436.54 & 14577.65 & 15188.33 \\
\hline & $v_{2}=0.10$ & $v_{2}=0.20$ & $v_{2}=0.30$ \\
\hline$V\left(S_{2}(t), K_{2}(t)\right)$ & 7950.38 & 8822.44 & 10330.36 \\
\hline
\end{tabular}

Note: $v_{1}$ is the volatility of the residential property market price, and $v_{2}$ is the volatility of the retail property market price. These scenarios are $50 \%$, $100 \%$, and $150 \%$ of the estimated $v_{1}$ and $v_{2}$ in Table 1 respectively.

Table 4. The estimated option value for the vertical mixed-use development

\begin{tabular}{|l|c|c|c|}
\hline \multicolumn{4}{|c|}{ Case 1 (original design): GFA1 = 151232 square meter, GFA2 $=209640$ square meter } \\
\hline & $v_{1}=0.06$ & $v_{1}=0.13$ & $v_{1}=0.20$ \\
\hline$v_{2}=0.10$ & 30646.40 & 30685.17 & 30739.67 \\
\hline$v_{2}=0.20$ & 31978.49 & 32430.36 & 32957.13 \\
\hline$v_{2}=0.30$ & 35217.45 & 35454.99 & 36368.89 \\
\hline
\end{tabular}

\begin{tabular}{|l|c|c|c|}
\hline \multicolumn{3}{|c|}{ Case 2: GFA1 $=288698$ square meter $(80 \%$ GFA), GFA2 = 72174 square meter (20\% GFA) } \\
\hline & $v_{1}=0.06$ & $v_{1}=0.13$ & $v_{1}=0.20$ \\
\hline$v_{2}=0.10$ & 22380.88 & 22444.16 & 22756.89 \\
\hline$v_{2}=0.20$ & 22445.05 & 22801.95 & 23426.48 \\
\hline$v_{2}=0.30$ & 22562.01 & 23272.16 & 24378.43 \\
\hline
\end{tabular}

developer has to start the construction for two uses at the same time in the vertical project. Hence, the total vertical project value has a lower profit potential than the individual residential/retail building value when the residential/ retail market becomes more volatile.

2. The critical height premium is bounded by the hurdle ratio. This premium increases as the retail market volatility grows. However, it does not have a consistent trend as the residential market volatility increases.

The relationship between the critical height premium and the hurdle ratio can be explained by the following inequality:

$$
\begin{aligned}
& \operatorname{Max}\left[0, S_{1}(t) \times e^{-\alpha \times X} \times A_{1}-K_{1}(t) \times A_{1}+C\right]< \\
& e^{-\beta \times X} \times \operatorname{Max}\left[0, S_{1}(t) \times A_{1}-K_{1}(t) \times A_{1}+C\right](\text { if } \alpha=\beta),
\end{aligned}
$$

where $e^{\alpha \times X}-1$ is the critical height premium and $e^{\beta \times X}-1$ is the hurdle ratio. To turn the above inequality into an equation, $e^{\alpha \times X}$ should decrease. Hence, $\alpha<\beta$.
The inconsistent trend of the critical height premium due to the residential market volatility is also related to the above inequality. Higher residential market volatility not only reduces $e^{\beta \times X}$ but also causes an upward pressure on the residential building value. As mentioned in the previous finding, the horizontal project value will increase faster than the vertical project value when the volatility grows. To ensure that the vertical project is more profitable, the critical height premium must increase. Then, this premium has a positive relationship with the residential market volatility and is also bounded by the hurdle ratio. The two opposite effects result in the inconsistent trend of the critical height premium.

This finding indicates that the developer will prefer the horizontal type if the retail market becomes more volatile. As a high volatility market, the time value of individual retail building is difficult to be compensated by the critical height premium. Meanwhile, the rapidly changing residential market may encourage or discourage the ap- 
plication of the vertical type. We should not make a judgement to accept the horizontal type or the vertical type only because of the increase of residential market volatility.

3. When the retail units have a greater total value in the vertical project than the residential units, the hurdle ratio and the critical premiums are larger. In other words, if the retail part is expected to generate the major income of the whole project, the mixed-use project is more likely to be horizontally developed, as higher critical premiums are required. By contrast, if the residential units are the major components of the project, the mixed-use project should be vertically constructed.

As mentioned, the retail market is not sensitive to the building height. The GFA for retail use is not related to the critical premium. The higher proportion of the residential units only leads to greater GFA for residential use. This outcome will reduce the critical height premium per square metre. In other words, a larger number of residential units dilute the minimum height premium to make the vertical project superior to the horizontal project. Hence, the developer prefers vertical mixed-use development when a high-rise residential building is included in the project.

\subsection{The fluctuation of construction cost}

According to the Hong Kong Report of Quarterly Construction Cost Update in December 2020 by Rider Levett Bucknall (2020), the construction cost from 2010 to 2015 rose by nearly $50 \%$ but dropped by $10 \%$ from 2016 to 2020. Arcadis Tender Price Index (Arcadis, 2020) rose from 1273 in 2009 Q4 to 1903 in 2014 Q4 and dropped to 1800 in 2019 Q4 (Figure 1). In each quarter from 2010 to 2015, this index rose monotonically. It was flat in 2016 and decreased monotonically from 2017 to 2019. For comparison, the Price Indices for Hong Kong Property Mar- ket (Rating and Valuation Department, 2020) contains more peaks and valleys during this decade. This trend explains that the fluctuation of the construction cost is much smaller than that of the market price. Although a stochastic process for construction cost is a better choice in mathematics, it plays a small role in the option pricing process in mixed-use development. Moreover, if two stochastic processes of the construction cost are introduced, the covariance among four stochastic processes should all be included to generate the paths of both prices and costs. This inclusion would raise the computational complexity in option pricing but may not increase much in the accuracy. Further studies can be conducted to improve this option pricing model to include more stochastic processes in costs without a significant increase in computational complexity.

\section{Conclusions}

Mixed-use developments are believed to contribute to the efficient land use in high-density cities in the past decades. The vertical type of mixed-use development, in which multiple uses are vertically distributed within the same building structure, has been growing in popularity in some Asian metropolitan areas. However, previous option pricing models for mixed-use developments do not indeed comply with the characteristics of the vertical type. In addition, some construction constraints only exist in this type. An appropriate theoretical model requires some adjustments to measure the flexibility and these constraints properly.

This study develops a new option pricing model for vertical mixed-use developments, especially for those which contain residential units for sale. Properties in multiple uses are constructed and delivered to customers simultaneously, and the maximum exercise time to

Arcadis tender price index

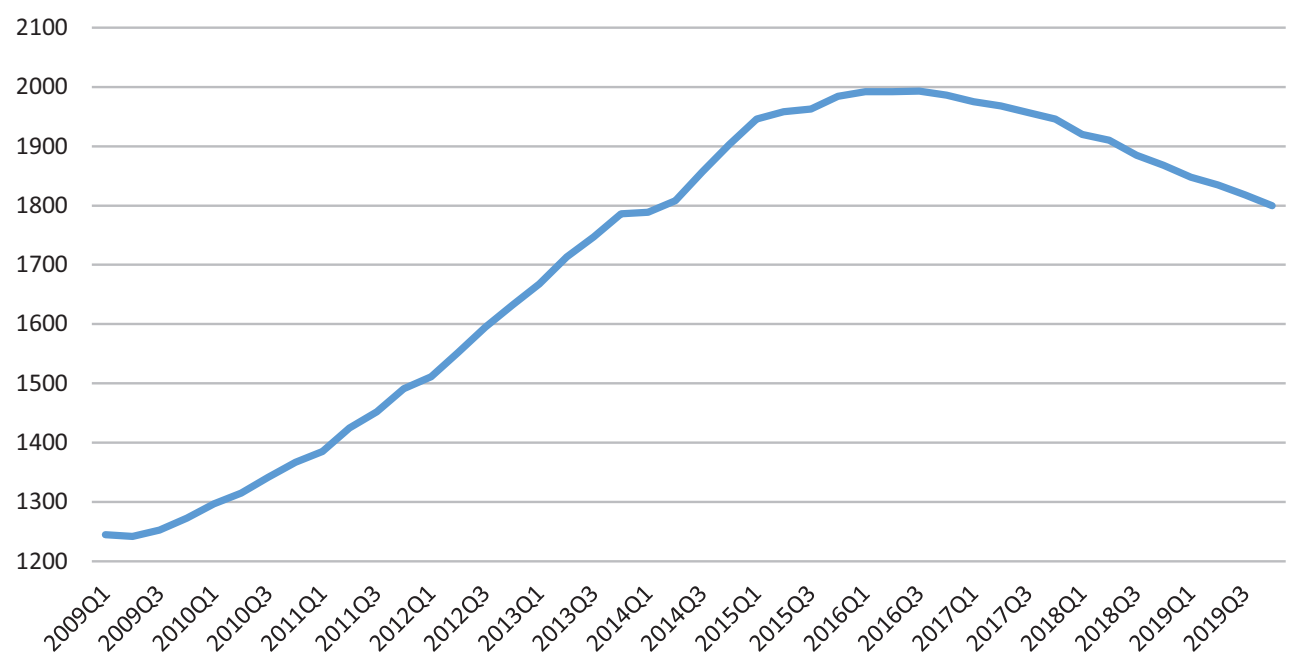

Figure 1. Arcadis tender price index (Base $=100$, at year 1970) (source: Arcadis, 2020) 
develop is usually constrained by the building covenants. Compared with real options for horizontal mixed-use developments, options for the vertical type have the height premium, as the upper structure can be sold at a higher price. Meanwhile, options for the horizontal type has a flexibility premium, as the structures for different uses can be constructed at separate timings.

The approach of least square Monte Carlo and monomial basic functions are applied to minimise the underestimation of this American basket option. This study has also derived an important determination method that can select between the vertical type and the horizontal type for a higher project value. A critical height premium is defined as the height premium which equals to the flexibility premium. An increasing critical height premium indicates a lower probability to develop the property in vertical type. If the lower floors of the mixed-use development are for retail use and the upper floors are for residential use, then the critical height premium has a positive relationship with the retail market volatility but has no consistent trend when the residential market volatility increases. A larger revenue from the retail use indicates a higher probability of being horizontally developed. This approach also provides a quantitative standard. If the height premium in the same district is higher than the critical height premium, then the vertical type is economically superior. The empirical discussions are based on the project information in Kung Tong City Centre in Hong Kong.

This study also considers cases in which the construction cost is a linear or a quadratic function of the building height. Accurate estimations of the construction cost require information from previous project constructions. This model can still be extended to consider the presales process for residential units and the volatility of two types of construction costs.

In summary, to value a vertical mixed-use project more accurately, careful considerations should be given to the limitations of the lease and the height premium for upper structures. This study has provided a useful concept of critical height premium that can be extended to the case of a compound option for horizontal developments. The comparison between two types of mixed-use development can allow the developer to consider the optimal development strategy. If the flexibility premium for the horizontal type is large enough, the developer can pay an additional fee to change the land lease to relieve the building constraint if possible. The measure of the critical height premium can also explain the developers' preferences in development types in the economic aspect. If the use of the rest of the buildings can be changed after some buildings have been completed in horizontal developments, the critical height premium in vertical developments would increase significantly. Meanwhile, strict lease restrictions for horizontal developments can promote the construction of vertical mixed-use buildings. The increase of the critical height premium depends on the embedded finite-time option value for the further change of use in some buildings in horizontal developments. This change requires an adjusted Monte Carlo method to value a compound finite- time American option on multiple assets in the future. Hence, further study is recommended to attempt to shed light on the application of vertical mixed-use development in an efficient urban redevelopment context.

\section{Acknowledgements}

This research is supported by the Fundamental Research Funds for the Central Universities (No. 19lgpy58), and National Natural Science Foundation of China (No. 42001177).

\section{Disclosure statement}

The authors do not have any competing financial, professional, or personal interests from other parties.

\section{References}

Arcadis. (2018). Construction cost handbook (in 2018). https:// www.arcadis.com/en/knowledge-hub/perspectives/asia/research-and-publications/construction-cost-handbook

Arcadis. (2020). Construction cost handbook (in 2020). https:// www.arcadis.com/en/knowledge-hub/perspectives/asia/research-and-publications/construction-cost-handbook

Abbas-Turki, L. A., \& Lapeyre, B. (2009, July 24-26). American options pricing on multi-core graphic cards. In 2009 International Conference on Business Intelligence and Financial Engineering (pp. 307-311), Beijing, China. https://doi.org/10.1109/BIFE.2009.77

Addae-Dapaah, K. (2005). Highest and best use in the valuation of mixed - use development sites: a linear programming approach. Journal of Property Research, 22(1), 19-35. https://doi.org/10.1080/09599910500411028

Bao, H. X., \& Wan, A. T. (2004). On the use of spline smoothing in estimating hedonic housing price models: empirical evidence using Hong Kong data. Real Estate Economics, 32(3), 487-507. https://doi.org/10.1111/j.1080-8620.2004.00100.x

Bookout, L. W. (1992). Neotraditional town planning: cars, pedestrians, and transit. Urban Land, 51(2), 15-20.

Capozza, D., \& Li, Y. (1994). The intensity and timing of investment: the case of land. The American Economic Review, 84(4), 889-904.

Childs, P. D., Riddiough, T. J., \& Triantis, A. J. (1996). Mixed uses and the redevelopment option. Real Estate Economics, 24(3), 317-339. https://doi.org/10.1111/1540-6229.00693

Choy, L. H. T., Mak, S. W. K., \& Ho, W. K. O. (2007). Modeling Hong Kong real estate prices. Journal of Housing and the Built Environment, 22(4), 359-368. https://doi.org/10.1007/s10901-007-9089-2

Coskan, C. (2008). Pricing American options by simulation [Doctoral dissertation]. Bogaziçi University.

Crafts, J. M. (1998). Impact of commercial development on adjacent residential properties. The Appraisal Journal, 66(1), 6-10.

Cybriwsky, R. (1999). Changing patterns of urban public space: observations and assessments from the Tokyo and New York metropolitan areas. Cities, 16(4), 223-231. https://doi.org/10.1016/S0264-2751(99)00021-9

DeLisle, J., \& Grissom, T. (2013). An empirical study of the efficacy of mixed-use development: the Seattle experience. Journal of Real Estate Literature, 21(1), 25-57.

https://doi.org/10.1080/10835547.2013.12090352 
Fisher, J. D., \& Martin, R. S. (2007). Income property valuation ( $3^{\text {rd }}$ ed.). Dearborn Real Estate Education.

Frank, L. D., \& Pivo, G. (1994). Impacts of mixed use and density on utilization of three modes of travel: single-occupant vehicle, transit, and walking. Transportation Research Record, 1466, 44-52.

Geltner, D., Riddiough, T., \& Stojanovic, S. (1996). Insights on the effect of land use choice: the perpetual option on the best of two underlying assets. Journal of Urban Economics, 39(1), 20-50. https://doi.org/10.1006/juec.1996.0002

Geoghegan, J., Wainger, L. A., \& Bockstael, N. E. (1997). Spatial landscape indices in a hedonic framework: an ecological economics analysis using GIS. Ecological Economics, 23(3), 251-264. https://doi.org/10.1016/S0921-8009(97)00583-1

Glasserman, P., \& Yu, B. (2004). Number of paths versus number of basis functions in American option pricing. The Annals of Applied Probability, 14(4), 2090-2119. https://doi.org/10.1214/1050516040000008461

Guma, A., Pearson, J., Wittels, K., de Neufville, R., \& Geltner, D. (2009). Vertical phasing as a corporate real estate strategy and development option. Journal of Corporate Real Estate, 11(3), 144-157. https://doi.org/10.1108/14630010910985904

Hoppenbrouwer, E., \& Louw, E. (2005). Mixed-use development: theory and practice in Amsterdam's Eastern Docklands. European Planning Studies, 13(7), 967-983.

https://doi.org/10.1080/09654310500242048

Hoyle, M. (2016). Pricing American options. https://ww2.mathworks.cn/matlabcentral/fileexchange/16476-pricing-american-options? focused $=6781450 \&$ tab $=$ function

Hughen, W. K., \& Read, D. C. (2017). Analyzing form-based zoning's potential to stimulate mixed-use development in different economic environments. Land Use Policy, 61, 1-11. https://doi.org/10.1016/j.landusepol.2016.11.010

Hui, E. C., Chau, C. K., Pun, L., \& Law, M. Y. (2007). Measuring the neighboring and environmental effects on residential property value: using spatial weighting matrix. Building and Environment, 42(6), 2333-2343.

https://doi.org/10.1016/j.buildenv.2006.05.004

Hui, E. C., Zhong, J. W., \& Yu, K. H. (2012). The impact of landscape views and storey levels on property prices. Landscape and Urban Planning, 105(1-2), 86-93.

https://doi.org/10.1016/j.landurbplan.2011.12.002

Jim, C. Y., \& Chen, W. Y. (2009). Value of scenic views: hedonic assessment of private housing in Hong Kong. Landscape and Urban Planning, 91(4), 226-234. https://doi.org/10.1016/j.landurbplan.2009.01.009

Jim, C. Y., \& Chen, W. Y. (2010). External effects of neighbourhood parks and landscape elements on high-rise residential value. Land Use Policy, 27(2), 662-670.

https://doi.org/10.1016/j.landusepol.2009.08.027

Jones Lang LaSalle. (2014). Resurgence of mixed-use developments in Singapore's CBD. http://www.ap.jll.com/asia-pacific/en-gb/ Research/Resurgence-of-Mixed-Use-Developments-in-Singapore-CBD.pdf

Kettler, R. C. (2005). Vertical community. Urban Land, 64, 11-12.

Koch, D. (2004). Looking up. Retail Traffic, 33(12), 38-42.

Kockelman, K. (1997). Travel behavior as function of accessibility, land use mixing, and land use balance: evidence from San Francisco Bay Area. Transportation Research Record: Journal of the Transportation Research Board, 1607, 116-125. https://doi.org/10.3141/1607-16

Lai, L. W., Chau, K. W., Yiu, E. C., Wong, K. S., Wong, W. S., \& Chan, P. Y. (2007). Measuring and interpreting the effects of a public-sector-led urban renewal project on housing pricesan empirical study of a comprehensive development area zone developed upon 'taking' in Hong Kong. Environment and Planning B: Planning and Design, 34(3), 524-538.

https://doi.org/10.1068/b31139

Lau, S. S., Giridharan, R., \& Ganesan, S. (2003). Policies for implementing multiple intensive land use in Hong Kong. Journal of Housing and the Built Environment, 18(4), 365-378. https://doi.org/10.1023/B:JOHO.0000005758.41003.19

Lau, S. S. Y., Giridharan, R., \& Ganesan, S. (2005). Multiple and intensive land use: case studies in Hong Kong. Habitat International, 29(3), 527-546. https://doi.org/10.1016/j.habitatint.2004.04.007

Lau, S. S., \& Zhang, Q. (2015). Genesis of a vertical city in Hong Kong. International Journal of High-Rise Buildings, 4(2), 117-125.

Levine, J., \& Frank, L. D. (2007). Transportation and land-use preferences and residents' neighborhood choices: the sufficiency of compact development in the Atlanta region. Transportation, 34(2), 255-274. https://doi.org/10.1007/s11116-006-9104-6

Liusman, E., Ho, D. C. W., Lo, H. C., \& Lo, D. Y. F. (2017). Office rents, mixed-use developments, and agglomeration economies: a panel data analysis. Journal of Property Investment \& Finance, 35(5), 455-471. https://doi.org/10.1108/JPIF-02-2017-0015

Longstaff, F. A., \& Schwartz, E. S. (2001). Valuing American options by simulation: a simple least-squares approach. The Review of Financial Studies, 14(1), 113-147. https://doi.org/10.1093/rfs/14.1.113

Mahan, B. L., Polasky, S., \& Adams, R. M. (2000). Valuing urban wetlands: a property price approach. Land Economics, 76(1), 100-113. https://doi.org/10.2307/3147260

Matthews, J. W., \& Turnbull, G. K. (2007). Neighborhood street layout and property value: the interaction of accessibility and land use mix. The Journal of Real Estate Finance and Economics, 35(2), 111-141. https://doi.org/10.1007/s11146-007-9035-9

Merton, R. C. (1973). Theory of rational option pricing. The Bell Journal of Economics and Management Science, 4(1), 141-183. https://doi.org/10.2307/3003143

Mok, H. M. K., Chan, P. P. K., \& Cho, Y.-S. (1995). A hedonic price model for private properties in Hong Kong. Journal of Real Estate Finance Economics, 10(1), 37-48.

https://doi.org/10.1007/BF01099610

Nasar, J. L., \& Julian, D. A. (1995). The psychological sense of community in the neighborhood. Journal of the American Planning Association, 61(2), 178-184.

https://doi.org/10.1080/01944369508975631

Pearson, J. R., \& Wittels, K. S. (2008). Real options in action: vertical phasing in commercial real estate development [Doctoral dissertation]. Massachusetts Institute of Technology.

Planning Department. (2002). Review of U.S. and Singapore experience in mix-use developments and its applicability to Hong Kong (Working Paper No. 15). https://www.pland.gov.hk/ pland_en/p_study/comp_s/hk2030/eng/wpapers/pdf/workingPaper_15.pdf

Rabianski, J., Gibler, K., Tidwell, O. A., \& Clements III, J. S. (2009). Mixed-use development: a call for research. Journal of Real Estate Literature, 17(2), 205-230. https://doi.org/10.1080/10835547.2009.12090251

Rating and Valuation Department. (2020). Private domestic price indices by class (Territory-wide) (from 1979). https:// www.rvd.gov.hk/en/property_market_statistics/index.html 
Rider Levett Bucknall. (2020). Hong Kong report: quarterly construction cost update. https://www.rlb.com/en/index/publicat ions/?geolocation=europe/

Rosen, S. (1974). Hedonic prices and implicit markets: product differentiation in pure competition. Journal of Political Economy, 82(1), 34-55. https://doi.org/10.1086/260169

Rowley, A. (1996). Mixed-use development: ambiguous concept, simplistic analysis and wishful thinking? Planning Practice \& Research, 11(1), 85-98. https://doi.org/10.1080/02697459650036477

Shen, L., He, Y., Li, L. H., \& Chau, K. W. (2020). Impacts of online shopping convenience and physical retail proximity on housing prices in Shenzhen, 2016-2018. Journal of Housing and the Built Environment, 35, 1157-1176. https://doi.org/10.1007/s10901-020-09732-w

Song, Y., \& Knaap, G. J. (2004). Measuring the effects of mixed land uses on housing values. Regional Science and Urban Economics, 34(6), 663-680. https://doi.org/10.1016/j.regsciurbeco.2004.02.003

Tu, C. C., \& Eppli, M. J. (1999). Valuing new urbanism: the case of Kentlands. Real Estate Economics, 27(3), 425-451. https://doi.org/10.1111/1540-6229.00779

Van Cao, T., \& Cory, D. C. (1982). Mixed land uses, land-use externalities, and residential property values: a reevaluation. The Annals of Regional Science, 16(1), 1-24. https://doi.org/10.1007/BF01287403

Ventolo, W. L., \& Williams, M. R. (2005). Fundamentals of real estate appraisal ( $9^{\text {th }}$ ed.). Dearborn Real Estate Education.

Vreeker, R., De Groot, H. L., \& Verhoef, E. T. (2004). Urban multifunctional land use: theoretical and empirical insights on econ- omies of scale, scope and diversity. Built Environment, 30(4), 289-307. https://doi.org/10.2148/benv.30.4.289.57157

Walker, H. (1997). Mixed use development as an agent of sustainability. In A. Coupland (Ed.), Reclaiming the city: mixeduse development. E \& FN Spon.

Wilhelmsson, M., \& Long, R. (2020). Impacts of shopping malls on apartment prices: the case of Stockholm. Nordic Journal of Surveying and Real Estate Research, 5, 29-48. https://doi.org/10.30672/njsr.95437

Xiao, Y., Hui, E. C., \& Wen, H. (2019). Effects of floor level and landscape proximity on housing price: a hedonic analysis in Hangzhou, China. Habitat International, 87, 11-26. https://doi.org/10.1016/j.habitatint.2019.03.008

Yao, H., \& Pretorius, F. (2014). Demand uncertainty, development timing and leasehold land valuation: empirical testing of real options in residential real estate development. Real Estate Economics, 42(4), 829-868. https://doi.org/10.1111/1540-6229.12052

Zhang, X. Q. (2000). High-rise and high-density urban form. In M. Jenks, \& R. Burgess (Eds.), Compact cities - sustainable urban forms for developing countries. Spon Press.

Zhang, L., Zhou, J., Hui, E. C., \& Wen, H. (2019). The effects of a shopping mall on housing prices: a case study in Hangzhou. International Journal of Strategic Property Management, 23(1), 65-80. https://doi.org/10.3846/ijspm.2019.6360

Zhu, W., \& Chiu, R. L. H. (2011). The planning and design of environmentally sustainable high-rises. In B. Yuen, \& A. GarOn Yeh (Eds.), High-rise living in Asian cities. Springer. https://doi.org/10.1007/978-90-481-9738-5_4 